\title{
Subjectivity and illness narratives
}

\author{
Renata Kokanović ${ }^{1} \cdot$ Jacinthe Flore $^{1}$
}

(C) Macmillan Publishers Ltd 2017

\section{Introduction}

Following Talcott Parsons' (1951) introduction of the concept of the "sick role" in the early 1950s, the fields of social sciences, psychology and critical medical humanities have witnessed an expansion of scholarly work seeking to refine, complicate, broaden and problematise Parsons' concept and ideas on the lived experience of illness (Burnham 2012, 2014; Shilling 2002; Charmaz 1999; Kleinmann 1988; McCormack 1981). A functionalist sociologist, Parsons, has been criticised for overlooking or glossing over several facets of the illness experience, for example, aspects of the doctor-patient relationship and power differentials, patients' challenges to medical expertise and agency, the role of carers, as well as dimensions of gender, class and race (see Burnham 2012, 2014). To address these complex questions, scholars in the medical humanities have increasingly turned to the narrative as a potent format to study and produce meaning on illness and existence (Hurwitz et al. 2004). Research informed by or located in the critical medical humanities, Whitehead and Woods (2016) suggest, continuously identifies novel ways of understanding (and problematising) health and illness by questioning structures of authority and expertise, interrogating the production of subjectivities and their fluid placements within socio-political and cultural changes. The critical medical humanities addresses not only the social, historical and cultural contexts of health and illness, it importantly investigates the "production, concrescence and dispersal" of such contexts "across the precarious, unequal and environmentally degraded societies in which we live" (Viney et al.

Renata Kokanović

renata.kokanovic@rmit.edu.au

1 RMIT University, School of Global, Urban \& Social Studies, Melbourne, VIC, Australia 
2015 , p. 2). It is with a view of adding to this growing body of literature on health and illness narratives and subjectivity that this first volume of a double special issue of Subjectivity is put together, providing a broad range of perspectives on pressing questions.

The essays in this special issue emerge from the "Broken Narratives and the Lived Body" conference held at the Monash University Prato Centre, Italy, in April 2016. A wide range of papers presented at the conference explored themes of embodied experiences of psychiatric diagnoses, neurological illnesses and cognitive "impairments"; persons who are neurodiverse (for example, people living with autism); psychological traumas; and life-threatening illnesses by paying attention to how illness stories are told and performed-as "situated practices" (Kokanović and Stone 2017). The conference and the essays in this special issue provide a critical space for understanding and theorising illness narratives bringing together scholars from across the social sciences, medicine, allied health and humanities. Together, they offer insights into how subjectivities are produced and experienced in the context of illness, caring for the elderly and injured family members, and they examine how these emerging and fluid subjectivities reshape the worlds of ill, injured and those concerned and caring about them. They emphasise the importance of experiences to biomedical understanding of illness, while at the same time raising questions of representation by inquiring into what extent (if at all) one person's subjective experience of illness could stand for others (Magi et al. 2016).

All the papers in this special issue offer complex readings of illness and care narratives and subjectivity as a process, highlighting the entwined character of illness, narrative form and function and their relationships to the formation of subjectivity and its fluidity. They collectively examine how forms of subjectivity are created, maintained and transformed through experiences of breast cancer (Greenhalgh 2017), traumatic brain injury (Mäkelä 2017), uncertain futures in the context of advanced cancer (Kenny, Broom, Kirby, Wyld and Lwin 2017), chronic pain (Barker 2017), and complex, existential angst and extreme tiredness caused by long-time caring for close elderly family members (Danely 2017). The papers in this collection chart narratives through which subjectivities are formed, reshaped and contested in the context of challenging illness experiences.

\section{Interruptions and assemblages}

The turn to theorisations about the subject and subjectivity has had significant importance for the development of the medical humanities and social sciences since the second half of the twentieth-century (for a detailed summary see the 2008 editorial of the first launch issue of Subjectivity by Blackman, Cromby, Hook, Papadopoulos and Walkerdine). Blackman et al. note that subjectivity "as any other concept is seen as an active agent that shapes and is shaped by prevailing social, cultural and political spaces" (Blackman et al. 2008, p. 14). To study and understand subjectivity then, it is necessary to consider its production and 
transformations within wider socio-political and cultural elements and relations of power.

In "Subjectivities: for better and for worse," Félix Guattari discusses subjectivity as "plural polyphonic" (1996, p. 193). He argues that while different circumstances or events may impact subjectivity, this is not limited to narrow, "univocal causality" (1996, p. 193). Reflecting on his mid-1950s study of La Borde, a psychiatric clinic in the Loire Valley, France, Guattari observes that many different aspects of a patient's journey shape and control their experience, including architecture, carers and economic relations (1996, p. 195). The environment, technology and people shaping and transforming subjectivity is termed by Guattari as "a configuration of collective assemblages of enunciation" (1996, p. 196). As Simon O'Sullivan (2008, p. 2) argues, it is crucial to think through "the complexity of processes that produce subjectivity, the mental and social ecologies that produce us as subjects". This production of subjectivity, dependent upon and produced by external circumstances and social structures, is insightfully analysed in Seamus Barker's essay "Subject to Pain" in this special issue. In this essay, Barker draws on the short narrative of Marcus, a man living with chronic neck pain, published on the website of an organisation advocating for people living with pain. The account, titled "Marcus: Injured Lifting a Child", demonstrates how Marcus went through different pedagogical processes. He needed to firstly acquire the language to narrate his pain in way that would elicit support. However, Barker reminds us that speaking about chronic pain does not evade the interlocutor from mobilising other discourses when heeding the speaker. As a result, dissonances emerge between the speaker and interlocutor (2017, p. 9). This is reminiscent of Judith Butler's argument that the terms by which we narrate our selves, and in Marcus' case, our pain, are never fully ours. We draw upon norms, ideas and beliefs to make ourselves intelligible, while the interlocutor undertakes a similar task to interpret the narrative (Butler 2005, p. 21). Hence, Barker's analysis continues, while the narrator may be cognisant of possibilities for dissonance, in the "scene of recognition" (Butler 2005, p. 22), when giving an account of chronic pain, Marcus draws on a common language to obtain diagnosis and support.

Coiled around and shaped by different norms, forces and institutions, subjectivity is always activity in production. Following Deleuze and Guattari, subjectivity can be approached as "decentered, as a part of an assemblage, an emergent conjunction and an evolving intertwining of self-ordering forces and diverse materialities" (Blackman et al. 2008, p. 15). It is always unfinished, interrupted, intricate and nonlinear. Subjectivity, as we will see below, exists only in the present while perpetually involving a complex relation to the past and the future.

Engaging with subjectivity as produced in illness narratives, Kenny et al's (2017) essay in this collection acknowledges the fraught, partial, unfinished and unfolding materialities of human bodies that cannot be fully captured into a single, coherent narrative. Illness narratives underscore the interruptions of subjectivity and the chaotic aspects of human lives. Narratives of living with advanced cancer reveal disorder, incoherence and coherence, "resist unificatory integration" and as such, Kenny et al. argue, "fall outside of coherent normativity" (2017, p. 2). Coherence appears to be a necessary element of narrative. Different elements need to be unified 
and temporally aligned in a chronological order. Coherence, then, is a normative requirement; it is understood as a necessity both by institutions and culture. In broad terms, an encounter with legal, medical or governmental institutions requires a coherent, ordered account of an event or set of events culminating in an action, demand or recognition. In a clinical encounter, anamneses are recorded, edited and supplemented by medical practitioners. Continuity between different events and encounters in the narrative is identified by Angela Woods as problematic particularly for the medical humanities because it potentially distracts from "systemic analysis of the diverse functions and effects of specific types of storytelling" (Woods 2011a, p. 74). Thus, in their paper, Kenny et al. problematise notions of "coherent normativity", which they contend, "marginalises dis-unity, uncertainty and precarity of bodily, temporal, and existential disarray" (2017, p. 15). Such privileging of narrative coherence in culture and medicine potentially obscures the fraught dimensions of the experience of cancer and risks threatening "the selfhood of those living in terminal anticipation" (p. 15). The authors' interrogation of narrative coherence in lived experiences of advanced cancer generates a set of complex discussions related to discourses of cancer "survivorship" (see Conway 2007), uncertainty and futurity, and narrative interruptions and consistency.

\section{Disrupting and suturing narratives}

The broad field of the humanities is chiefly concerned with the complex nature of the subject and subjectivity, its formation, transformation and contradictions in social, economic and cultural worlds. Taking medicine and its network of norms, expertise, industry and consumption, the critical medical humanities locates and examines processes of subject formation and subjectivity within the context of encounters with technologies of diagnosis, treatment and recovery, to name only a few. Inquiring into the formation of subjectivities, the critical medical humanities place them in their plural contexts while considering the influence of historical discourses and the nature of experience. In other words, the emergence of and challenges to subjectivity is inextricable from the study of lived experiences of illness. Examining stories of illness experiences can have therapeutic, professional as well as practical benefits for researchers and the ill. In the critical medical humanities, "a person's narrative is often held to be coextensive with their subjective experience, their psychological health and indeed their very humanity" (Woods 2014, p. 114). This, Woods observes, results in a privileging of narrative and storytelling as "fundamentally healthy and desirable" (2011a p. 75). In a series of essays (Woods 2011a, b, 2014; see also Woods 2013) where she engages with Strawson's “Against narrativity" (2004) and Frank's The Wounded Storyteller (1995) in particular, Woods suggests that scholars in the medical humanities should consider that narrative "does not have the monopoly on expressivity" (2014, p. 124). Thus, she suggests, illness does not necessarily call for or require stories (2011a, p. 77). Woods gestures towards the tools afforded by philosophy and phenomenology as possible supplements or even alternatives to the narrative form 
(2014, p. 125 and 2011a, p. 76; see Carel 2011). However, McKechnie (2014, p. 120) notes, non-narrative representation and communication require a narrative response in interpretation and meaning-making. The critical medical humanities provide fertile ground for provoking debates on the uses of narratives and Woods calls for the field to "attend to what cannot be spoken; to embrace silence as part of life that is open to contingency and randomness, but also to ecstasy and intensity" (2014, p. 126). Narrative is problematic and requires problematisation (McKechnie 2014 , p. 123). As a medium and a practice, it is integral for producing knowledge and relies on norms that Kenny et al. (2017) in this special issue interrogate. We need to consider how subjectivities are both articulated through narrative and can also be conditioned by the norms that govern the articulation of narrative. We would suggest that narratives are not necessarily teleological or orientated towards "a future made psychologically healthier" (Woods 2014, pp. 124-125). Kenny et al's (2017) essay demonstrates that the future remains uncertain, and the experience of advanced cancer produces futurity as precarious, doubtful and desirable. By questioning the dominance of narrative coherence, the authors uncover an incoherence that is always a possibility of narrative, a possibility albeit tamed and silenced by the normativity of coherence.

As a contribution to the critical medical humanities, we would like this special issue to be framed as an effort to utilise, illuminate and disrupt the instrument of narrative. Kenny et al's (2017) essay examines both the norm of narrative coherence and the assumption of denouement and closure in illness narratives. Jason Danely's (2017) essay in this special issue examines the active shaping and transformation of family carers' subjectivity and experiences of extreme fatigue. Danely alerts us to the potential excesses and divergences involved in narratives of care and exhaustion. He persuasively observes that in exceeding the narrative context of carers, thus placing further demands upon carers' subjectivity, "the ethical demand of care is intensified, and fatigue endured" (2017, p. 2). The experience of fatigue, ongoing and accumulating over time, simultaneously disrupts and structures the subjectivities of carers; it represents an intensity that cannot be fully capture in narrative and is characterised by Danely as a form of excess that "expands the bounds" of narrative context (2017, p. 2). A participant in Danely's research for example notes the difficulty of putting exhaustion into words: "I can't describe in any other way, the tsunami effect" (Danely 2017, p. 12). The importance of Danely's analysis lies in its implications of the experience of exhaustion for carer support and recognition. In other words, if the fatigue experienced by carers is not recognised, addressed and supported by socio-cultural narratives, carer fatigue can have tragic outcomes. In Danely's critique, fatigue is neither a mere by-product of care-giving nor a "devil" that must be expelled through building resilience and producing meaning. Instead, it is more productively approached as an integral element of care-giving; "a brokenness that allows for a reorganization of carer subjectivity and deserves recognition and space" (Danely 2017, p. 14).

Through the ongoing responsibilities of care and the experience of fatigue, carers' subjectivities are reorganised and sutured. The subject as carer can only be articulated through the language and norms available to carers, which may not do justice to the efforts, demands, love and pain involved in care-giving-experiences that do not 
easily suit the norms of the narrative form. While acknowledging that narratives are always ideologically grounded, the exploration of subjectivity through the analysis of self-representation and multiple storytelling, which highlights the multifaceted and diverse realities of peoples' experiences by bringing to the fore complex identities, benefits narrative research on illness and carer experiences (Bloom 1996, p. 193).

\section{Sensing the subject}

Understanding the world in certain way arises from the subjective understanding that characterises it; thus, "the existence of the experiences in the world is inseparable from the existence of subjects in it" (Guillot 2016, p. 27). In this manner, any episode of experiencing necessarily involves a subject of experience in the world (Strawson 2017, p. 250). The subject is embodied and embedded in multifarious physical, social and historical environments. The constitution of the subject is a social process; we are selves not by individual right or in isolated circumstances. Rather, it is only through relations to others-who may be close others, distant acquaintances and institutional entities. Drawing on the writings of Maurice Merleau-Ponty, Dan Zahavi (2008, p. 163) notes that subjectivity is always a relation to the world; "[subjectivity] is not hermetically sealed up within itself, remote from the world and inaccessible to the other". In our encounter with others, human and non-human, our subjectivity is affected, troubled and transformed.

In her contribution to this special issue, Trisha Greenhalgh (2017) presents an autoethnography of her experience of breast cancer and chemotherapy. In her essay, she considers the value of an intimate, personal narrative of illness and treatment, in juxtaposition with so-called "academic" writing. The latter form of writing, which possesses a set of rules pertaining to language, coherence, argument and referencing, has been the prime style through which experiences of illness have been used, analysed and disseminated. However, of course, the Internet is continually proven as a formidable location where first-person narratives of illness, adventures in clinical settings, experimental treatments and recovery are featured (see Conrad and Bandini 2016). Greenhalgh's auto-ethnography, from the multiple positions of scholar, doctor and patient, complicates and questions lionised "expert" authority, and unpacks the relationship between who is recognised as a specialist and how experiential knowledge should/could influence practices of diagnosis, health care and health policy broadly speaking. Subjectivity, as produced through encounters with institutions and others, which includes medical professionals, intimate others and objects such as chemotherapy drugs and saline solution, is central to the development of Greenhalgh's narrative and her analysis. To be, and "tell", a self necessitates the presence of others. In the context of "deep illness", the illness narrative, Greenhalgh argues $(2017$, p. 6), "is not merely a text but an unfolding encounter between the wounded storyteller and his or her audience(s)" (see also Frank 1995, 1998).

The importance of the audience in the scene of address resonates with Barker's essay in this special issue, which identifies in Marcus' narrative the emergence of the narrator's subjectivity as active (inter)relations between his position as a subject, different models or discourses of pain, and medical institutions and clinical settings. 
Barker considers the implications of medico-scientific discourses, and their narrative techniques, as they congeal around the signifier "pain". Barker's analysis of the short personal narrative provides insights into the operation of those various, conflicting discourses and their impact on causal and moral responsibility for pain when they circulate in (and as) narrative. This, Barker suggests, is combined with Marcus' awareness of his audience and complicates his own understanding of subjectivity.

How subjectivity is produced in the context of illness experiences, and how it should be theorised, have been widely discussed and will no doubt continue to animate social theory, the humanities, biomedicine and auto-ethnographic texts on illness experiences. These discussions include theorising and articulation of subjectivity as well as reflexive lived experiences of health and illness (Van Hooft 1997, p. 23). Health (and illness) experience is more than the apparent state of a person's body; it is a condition of that person's subjectivity (Van Hooft 1997, p. 24). As any subjective experience can only be articulated by a person having that experience, attaining an empathetic understanding of that experience requires selfreflection of those engaging in the subjective experiences of others.

Mäkelä's (2017) paper in this special issue examines the narratives of a nineteenyear-old man, Toby, who suffered a traumatic brain injury following a bicycle accident, and his mother. In her analysis, Mäkelä explores tensions inherent in articulations of identity and subjectivity that circulate in both narratives. The young man's negotiation of his "pre-injury" self and his navigation of the healthcare system is contrasted and aligned with his mother's account of similar events, as well as her position as a "carer". Their narratives reveal entwined subjectivities conditioned and transformed through their traversing of the medical system and family responses to the injury. The tension, Mäkelä highlights, emerges as the mother endeavours to support her son while fulfilling her role as a parent and carer (2017, p. 12). Importantly, Mäkelä demonstrates that Toby's wider family's narrative assumption that he is a "broken self" overlooks the "transformative potential within ways of being" (2017, p. 13). Mäkelä identifies a similar narrative among the healthcare professionals that Toby encounters. Toby's sense of self does not align neatly with the idea of a "broken self".

By taking subjective experiences into account, aspects of health(care) that are framed by drawing on biomedicine can be most productively unpacked, questioned and deconstructed (Stam 2000, p. 274). Conceptualising lived, subjective experiences of illness experience needs to demonstrate an awareness of how they are informed, partially and in unexpected ways, by discourses of biomedicine. "The subject", Barker writes in this volume, "is both highly constrained by discourse, but not fully determined by it" (2017, p. 17). The intention, then, is not to fully discard biomedicine and somehow uncover a subject "untouched" by medical norms and technologies. Indeed, as Viney et al. (2015, p. 4) observe, the critical medical humanities cannot (and should not) attempt to fully jettison the life sciences; "the practices that make up the medical humanities are deeply and irrevocably entangled in the vital, corporeal and physiological commitments of biomedical research". Rather, we need to demonstrate how the narratives on which biomedicine relies, while dominant, are themselves prone to slippages, dissonances and reductionisms. 
As Mäkelä demonstrates, attention should be focused on subjective illness experiences, how they are sensed and understood by the ill, and as situated in culture, class, gender norms, power and knowledge.

Engagement with subjective experiences of health and illness should be principally governed by its reflexive properties, while considering the complex power and moral relations involved in the production of subjectivities that are premised on specific social, linguistic and cultural aspects and the complex power relationships within them. The question of moral reflexivity provides new grounds for talking about and understanding subjective experiences of health and illness (Stam 2000, p. 280). Kathryn Pyne Addelson (1994) argues that those doing research or providing health care are socially embodied actors who not only do professional work but, in doing so, are also significant moral and political actors (Stam 2000, p. 279; see Mäkelä, 2017). From different perspectives, but in a similar vein, all contributors to this special issue draw attention to the judgements and norms present in narratives disseminated by the moral and political actors encountered during the journey through clinical settings and recovery.

\section{Subjectivity and others}

Subjectivity is an ongoing process, and it can only be thought of in terms of becoming. While it relies on narrative, it is not fully captured by stories. In addition, it also depends on the stories that others tell about us. All papers in this special issue, apart from Greenhalgh, are interpretations and analyses of the illness experiences of others. In analysing the experiences and subjectivity of others, scholars are also involved in the production of narrative. It is important, then, to think of narratives and subjectivity as a dynamic relation, which encompasses different perspectives (and traditions of writing) on a subject. While we may reject or have conflicting interpretations of stories told about us, or the stories in which we feature, they nonetheless impact on our subjectivity (Zahavi 2014, p. 55). In addition, the simultaneity of events passing by, noted, remembered and forgotten impact on the subject in various, sometimes unknowable ways.

Thus, the inclusion of particular events takes into account multiple occurrences and incidents that have already happened (or things that we speculate are likely to happen). We take ownership of events and experiences by including them in our self-narrative (Zahavi 2014, p. 56). Through experiencing the other, and living a life deeply entwined with that of the other, narratives of subjectivity are continually revised. As Butler notes, engaging with Adriana Cavarero's writings, we depend, quite fundamentally, on the other; "we cannot exist without addressing the other and without being addressed by the other" (2005, p. 31). The carer narratives discussed in Danely's essay attempt to maintain barriers between their subjectivity and that of the person for whom they care. However, through the experience of extreme fatigue that cannot be easily articulated, such barriers become weakened and fractured, leaving carers to suture subjectivity through exhaustion, intimacy and vulnerability. 


\section{Unfinished narrative conclusions}

To tell a story about one's own life is not simply recounting facts; it is an interpretative achievement (Bruner 2003; Zahavi 2014). Far from mere archives of occurrences, stories are assembled in often-chaotic ways involving strands of memories, conflicting interpretations and condensations. The chaos and complexity of our lives, and the moments that escape notice, cannot be fully captured or collapsed into a single, coherence narrative. The narrator, speaker and indeed protagonist, will endeavour to establish coherence, synchronicity, chronology and, importantly, closure on sets of events. In this sense, desire is inherent to the production of narrative, desire for meaning, denouement and closure. However, closure is always related to a horizon that can only be partially attained. The narratives of subjectivity in illness do not end with health. As Greenhalgh demonstrates, one can return to narratives of illness and uncover new, oblique perspectives. The desire for narrative and its entanglement with the production of subjectivity is reflected in different ways in all the papers in this volume; in Barker's essay, Marcus' subjectivity in his experience of pain (and talking about pain) is shaped and transformed through his endeavours to engage with medical discourse; Kenny et al's analysis reveals the dominance and consequences of narrative coherence within fraught, chaotic experiences of subjectivity and futurity; Danely's analysis uncovers tensions in the production of subjectivity of carers through the experience of exhaustion and the desire for space; Mäkelä demonstrates how discourses of "broken" or "lost" self do not always resonate with the person injured who instead experiences brain injury "as an unattended component of his reflexive self” (2017, p. 12); and finally, Greenhalgh's compelling auto-ethnographic account reveals a desire for narrative as actively healing (2017, p. 16).

Narratives are never solely our own to produce and tell. In addition to the various norms that we continually negotiate, narrating a life is profoundly intertwined with the stories of proximate and distant others. The stories these others tell about this life, and their own lives, create multiple lattice-like structures, which are both fragmented and irrevocably connected. As we come into contact with embodied, ordinary and extraordinary experiences of illness, medical discourses and clinical institutions, our stories contort, break away and merge while remaining firmly embedded in larger historical, institutional and culturally specific structures. The vocabulary, traditions and theories we produce to narrate a self then are not universal tools; they fluctuate according to class, culture and historical period (Zahavi 2008, p. 109). In narrating subjectivity in illness, we may draw on strategies and tools to make ourselves intelligible and obtain support or care. Yet, such strategic mobilisations of language and discourse remain contained by institutional, medico-legal and political oversight, with which we maintain uneasy, ambivalent and complicit relations.

Acknowledgements The conference "Broken Narratives and the Lived Body" was held at the Monash University Prato Centre, Italy in April 2016 and funded by the Arts Faculty, Monash University, Melbourne. It was organised by Renata Kokanović in collaboration with Senka Božić-Vrbančić (University of Zadar), Ana Dragojlović (University of Melbourne), and Lars-Christer Hydén (Linköping University). We would like to express our gratitude to Senka and Ana for their comments on the first 
drafts of papers that comprise this special issue. Thank you to Jelena Kupsjak (University of Zadar) for administrative support. We also wish to thank the editors of Subjectivity for supporting the production of the double special issue, and the anonymous reviewers who have provided thoughtful feedback to all papers. Renata Kokanović is grateful to RMIT University whose generous support through RMIT Vice Chancellor's Senior Research Fellowship allowed her to complete work on this special issue.

\section{References}

Addelson, K.P. 1994. Moral passages: Toward a collectivist moral theory. New York: Routledge.

Barker, S. 2017. Subject to pain: Ricoeur, Foucault, and emplotting discourses in an illness narrative. Subjectivity, advance online publication, 22 August, doi: 10.1057/s41286-017-0035-9.

Blackman, L., J. Cromby, D. Hook, D. Papadopoulos, and V. Walkerdine. 2008. Creating subjectivities. Subjectivity 22 (1): 1-27.

Bloom, L.R. 1996. Stories of one's own: Nonunitary subjectivity in narrative representation. Qualitative Inquiry 2 (2): 176-197.

Bruner, J. 2003. Making stories: Law, literature, life. Cambridge: Harvard University Press.

Burnham, J.C. 2012. The death of the sick role. Social History of Medicine 25 (4): 761-776.

Burnham, J.C. 2014. Why sociologists abandoned the sick role concept. History of the Human Sciences 27 (1): 70-87.

Butler, J. 2005. Giving an account of oneself. New York: Fordham University Press.

Carel, H. 2011. Phenomenology as a resource for patients. Journal of Medical Philosophy 37 (2): $96-113$.

Charmaz, K. 1999. From the "sick role" to stories of self. In Self, social identity, and physical health: Interdisciplinary explorations, vol. 2, ed. R.J. Contrada, and R.D. Ashmore, 209-239. New York: Oxford University Press.

Conrad, P., and J. Bandini. 2016. Illness and the internet: From private to public experience. Health: An Interdisciplinary Journal for the Social Study of Health, Illness and Medicine 20 (1): 22-32.

Conway, K. 2007. Illness and the limits of expression. Ann Arbor: The University of Michigan Press.

Danely, J. 2017. Carer narratives of fatigue and endurance in Japan and England. Subjectivity, advance online publication, 6 September, doi: 10.1057/s41286-017-0037-7.

Frank, A.W. 1995. The wounded storyteller: Body, illness, and ethics. Chicago: The University of Chicago Press.

Frank, A.W. 1998. Just listening: Narrative and deep illness. Families, Systems \& Health 16 (2): 197-212.

Greenhalgh, T. 2017. Adjuvant chemotherapy: An autoethnography. Subjectivity, advance online publication, 21 August, doi: 10.1057/s41286-017-0033-y.

Guattari, F. 1996. Subjectivities: For better and for worse. In The Guattari reader, ed. G. Genosko, 193-203. Oxford: Blackwell.

Guillot, M. 2016. I me mine: On a confusion concerning the subjective character of experience. Review of Philosophy and Psychology 8 (1): 23-53.

Hurwitz, B., T. Greenhalgh, and V. Skultans (eds.). 2004. Narrative research in health and illness. Oxford: Blackwell.

Kenny, K., Broom, A., Kirby, E., Wyld, D. and Lwin, Z. 2017. Temporal anticipation: Entanglements of affect and temporality in living with advanced cancer. Subjectivity, advance online publication, 1 September, doi: 10.1057/s41286-017-0034-x.

Kleinmann, A. 1988. The illness narratives: Suffering, healing and the human condition. New York: Basic Books.

Kokanović, R. and Stone, M. 2017. Listening to what cannot be said: Broken narratives and the lived body. Arts \& Humanities in Higher Education, advance publication, 27 September, doi: 10.1177/ 1474022217732871.

Magi, J., N. Jones, and T. Kelly. 2016. How are/our work: "What, if anything is the use of any of this?". In The Edinburgh companion to the critical medical humanities, ed. A. Whitehead, and A. Woods, 136-153. Edinburgh: Edinburgh University Press.

Mäkelä, P. 2017. "They brought you back to the fact you're not the same": Sense of self after traumatic brain injury. Subjectivity, advance online publication, 29 August, doi: 10.1057/s41286-017-0036-8.

McCormack, T. 1981. The new criticism and the sick role. Canadian Review of Sociology and Anthropology 18 (1): 30-47. 
McKechnie, C.C. 2014. Anxieties of communication: The limits of narrative in the medical humanities. Medical Humanities 40 (2): 119-124.

O’Sullivan, S. 2008. Academy: The production of subjectivity. In: Irit Rogoff (ed.) Academy. Frankfurt: Revolver, pp. 238-244. http://www.simonosullivan.net/art-writings/production-of-subjectivities.pdf. Accessed 28 September 2017.

Parsons, T. 1951. The social system. Illinois: The Free Press.

Shilling, C. 2002. Culture, the "sick role" and the consumption of health. British Journal of Sociology 53 (4): 621-638.

Stam, H.J. 2000. Theorizing health and illness: Functionalism, subjectivity and reflexivity. Journal of Health Psychology 5 (3): 273-283.

Strawson, G. 2004. Against narrativity. Ratio 17: 428-452.

Strawson, G. 2017. The subject of experience. Oxford: Oxford University Press.

Van Hooft, S. 1997. Health and subjectivity. Health: An Interdisciplinary Journal for the Social Study of Health, Illness and Medicine 1 (1): 23-36.

Viney, W., F. Callard, and A. Woods. 2015. Critical medical humanities: Embracing entanglements, taking risks. Medical Humanities 41 (1): 2-7.

Whitehead, A., and A. Woods. 2016. Introduction. In The Edinburgh companion to the critical medical humanities, ed. A. Whitehead, and A. Woods, 1-31. Edinburgh: Edinburgh University Press.

Woods, A. 2011a. The limits of narrative: Provocations for the medical humanities. Medical Humanities 37 (2): 73-78.

Woods, A. 2011b. Post-narrative: An appeal. Narrative Inquiry 21 (2): 399-406.

Woods, A. 2013. Rethinking "patient testimony" in the medical humanities: The case of Schizophrenia Bulletin's first person accounts. Literature and Science 6 (1): 38-54.

Woods, A. 2014. Beyond the wounded storyteller: Rethinking narrativity, illness and embodied selfexperience. In Health, illness and disease: Philosophical essays, ed. H. Carel, and R. Cooper, 113-128. London \& New York: Routledge.

Zahavi, D. 2008. Subjectivity and selfhood: Investigating the first-person perspective. Cambridge: MIT Press.

Zahavi, D. 2014. Self \& other: Exploring subjectivity, empathy and shame. Oxford: Oxford University Press.

Renata Kokanović is Professor of the Sociology of Health and Illness and RMIT Vice Chancellor's Senior Research Fellow. She leads the Health, Society and Medicine Research Program in the School of Global, Urban and Social Studies at RMIT University. She is also Adjunct Professor in the School of Social Sciences at Monash University, Melbourne. Her research explores narratives of experiences attracting psychiatric diagnoses, and more recently narratives of cancer. She has published widely on mental health and illness, including in Social Science \& Medicine and Sociology of Health \& Illness. She is the Director of the research collaboration Healthtalk Australia (http://healthtalkaustralia.org/).

Jacinthe Flore is an early career researcher in the Health, Society and Medicine Research Program, School of Global, Urban and Social Studies at RMIT University, Melbourne. She has published journal articles on the history of discourses psychiatry and sexuality, and is currently revising a book manuscript titled Sexual Appetites: A History of Balance, Technique and Subjectivity. 